\title{
Effect of Microwave and Conventional Heating on the Cure Cycles of Particulate Reinforced Polymer Matrix Composites
}

\author{
Adefemi O. Adeodu ${ }^{1,}$, , Christopher O. Anyaeche ${ }^{1}$, Oluleke O. Oluwole ${ }^{2}$, Charles U. Omohimoria ${ }^{3}$ \\ ${ }^{1}$ Department of Industrial and Production Engineering, University of Ibadan, Ibadan, Nigeria \\ ${ }^{2}$ Department of Mechanical Engineering, University of Ibadan, Ibadan, Nigeria \\ ${ }^{3}$ Department of Petroleum and Chemical Engineering, Afe Babalola University, Ado Ekiti, Nigeria
}

Email address:

femi2001ng@yahoo.com (A. O. Adeodu), osita.anyaeche@ui.edu.ng (C. O. Anyaeche), oluwoleo2@asme.org (O. O. Oluwole), Charles_4real@yahoo.com (C. U. Omohimoria)

\section{To cite this article:}

Adefemi O. Adeodu, Christopher O. Anyaeche, Oluleke O. Oluwole, Charles U. Omohimoria. Effect of Microwave and Conventional Heating on the Cure Cycles of Particulate Reinforced Polymer Matrix Composites.International Journal of Materials Science and Applications.Vol. 4, No. 4, 2015, pp. 229-240. doi: 10.11648/j.ijmsa.20150404.12

\begin{abstract}
Polymer composites by and large found suitable for many specific applications in the field of electrical, electronics, marine, aerospace and microelectronics. Thus a new technique for processing polymer composites has been explored and one such is microwave curing. The roles of microwave in the post curing of polymer matrix composites cannot be under estimated, as it has the capacity to reduce the undue lengthy cure cycle and also improve the mechanical properties of the composite produced. The aim of the study is to determine the effect of microwave post curing on the cure cycles of the unsaturated polyester composites reinforced with aluminum and carbon black. This effect was compared with that post cured using conventional oven with the objective of investigating the significance of microwave curing on the curing time of the produced composites. A specific study comprising of aluminum filled polyester based composite and carbon black filled polyester based composite were investigated using two different composite curing methods (microwave and conventional autoclave heating). The investigation, through experimentation was based on temperature profile in term of heating rate and cure characteristics in term of degree of cure of the produced composites. Comparing the results of the post-curing of the composites using microwave and conventional methods, $30 \%$ aluminum filled cured at $94^{0} \mathrm{C}, 20 \%$ aluminum filled cure $92^{0} \mathrm{C}$, while $10 \%$ aluminum filled cured at $84^{\circ} \mathrm{C}$. Also, it took 20 minutes and 15 minutes for aluminium filled polyester and carbon black filled polyester composites respectively to reach ultimate cure in microwave system as compared to conventional autoclave system that takes the composite samples 290 minutes and 170 minutes respectively to get to the ultimate cure. It was concluded that post-curing of the particulate composites through microwave is able to achieve good heating rate and better control of temperature as compared to the conventional autoclave curing.
\end{abstract}

Keywords: Conventional Autoclave, Degree of Cure, Microwave, Polymer- Matrix Composites, Rate of Heating

\section{Introduction}

Electromagnetic energy has been employed for many years for industrial applications, including wood drying and bread processing [1]. There are several ways in which electromagnetic energy can be applied, such as induction, radio-frequency (RF) or microwave [1]. The main difference is the frequency at which these techniques operate. Depending on the material to be processed, the different frequencies can offer different levels of performance [1].
Although RF and microwave operate in a similar way, microwaves can offer better uniformity. However, both RF and microwave are usually limited to dielectric materials with specific dipolar properties [1].

The application of microwave curing to polymers and polymeric composites has been pursued worldwide over the past three decades [2]. Microwave processing offers many advantages over the conventional autoclave processing [2]. Rapid volumetric heating in microwave processing would significantly reduce cycle times and additionally, since power is applied directly to the material, the need to heat processing 
equipment is avoided and energy requirement are further reduced. In conventional autoclave processing, energy is transferred to the material through convection, conduction and radiation of heat from the mould surfaces resulting in long cycle time and high-energy requirements [2]. Thermal gradient during the processing can result in uneven cure, residual stresses and defects in the resultant composites [2].

Unsaturated polyester resins are commonly used as matrices for particulate reinforced composites. Commercial systems are generally supplied as relatively low molecular mass, unsaturated linear polyesters, dissolved in a polymerizable monomer such as styrene, providing crosslinking units by reacting with the unsaturated resin in a radical addition reaction. In addition, thickening agents, low profile additives, inert and reinforcing fillers, are added to the compound in order to modify the performance of the product. Finally, initiators, inhibitors, and other additives are added to control the reaction kinetics [3].

The process of cure of thermosets consists of two main stages: the heating period of the liquid resin (either pure or in the form of composites with fillers) and the cure reaction in the mould [4]. The cure behaviour of the unsaturated polyester resins is characterized by a complex mechanism involving copolymerization of the polyester and styrene molecules induced by the decomposition of an initiator.Illustrated in figure 1.1 , is the simplified reaction process of polyethylene. The ethylene molecules, $\mathrm{C}_{2} \mathrm{H}_{2}$, were added with an initiator (hardener). In this case hydrogen peroxide $\left(\mathrm{H}_{2} \mathrm{O}_{2}\right)$ provides free and reactive hydrogen radicals. With application of heat or pressure, these radicals break the double $\mathrm{C}=\mathrm{C}$ bonds of the ethylene molecules. This leaves an unreacted end which is now free to break other $\mathrm{C}=\mathrm{C}$ bonds in a similar manner. The process then continues to form a long polyethylene molecule through this chain reaction.

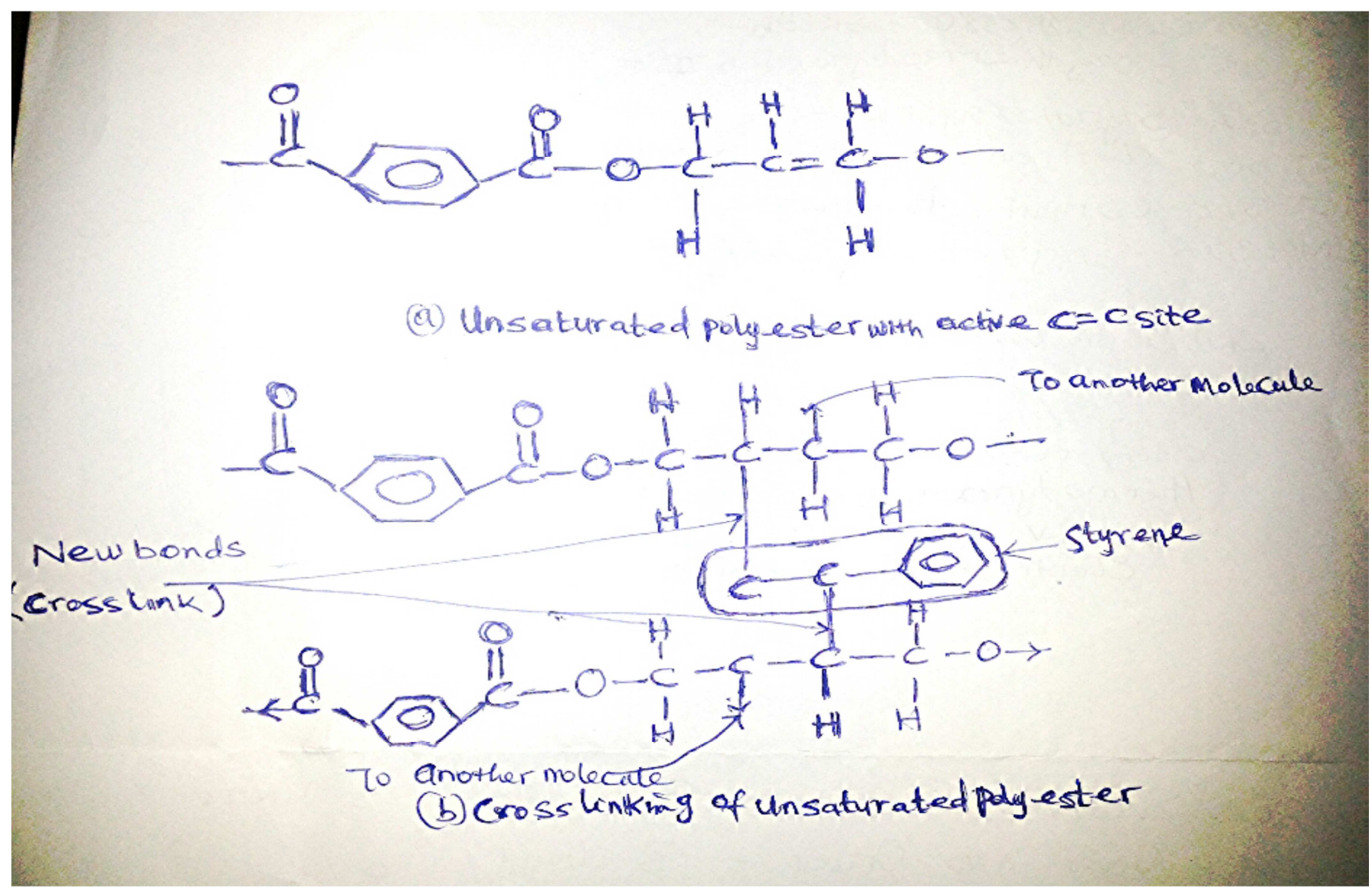

Source: [5]

Figure 1.1.(a) Reaction chain between $\mathrm{C}_{2} \mathrm{H}_{2}$ molecule reacting with free hydroxyl radical (OH) from the $\mathrm{H}_{2} \mathrm{O}_{2}$ initiator (b) cross linking of unsaturated polyester.

A more typical matrix used in the manufacture of AFRCs is epoxy resins [5]. The structure of a DGEBA (diglycidyl ether bisphenol- A) epoxy and amine hardener, DDM (4, 4-Diamino diphenyl methane) is shown in figure 1.2 


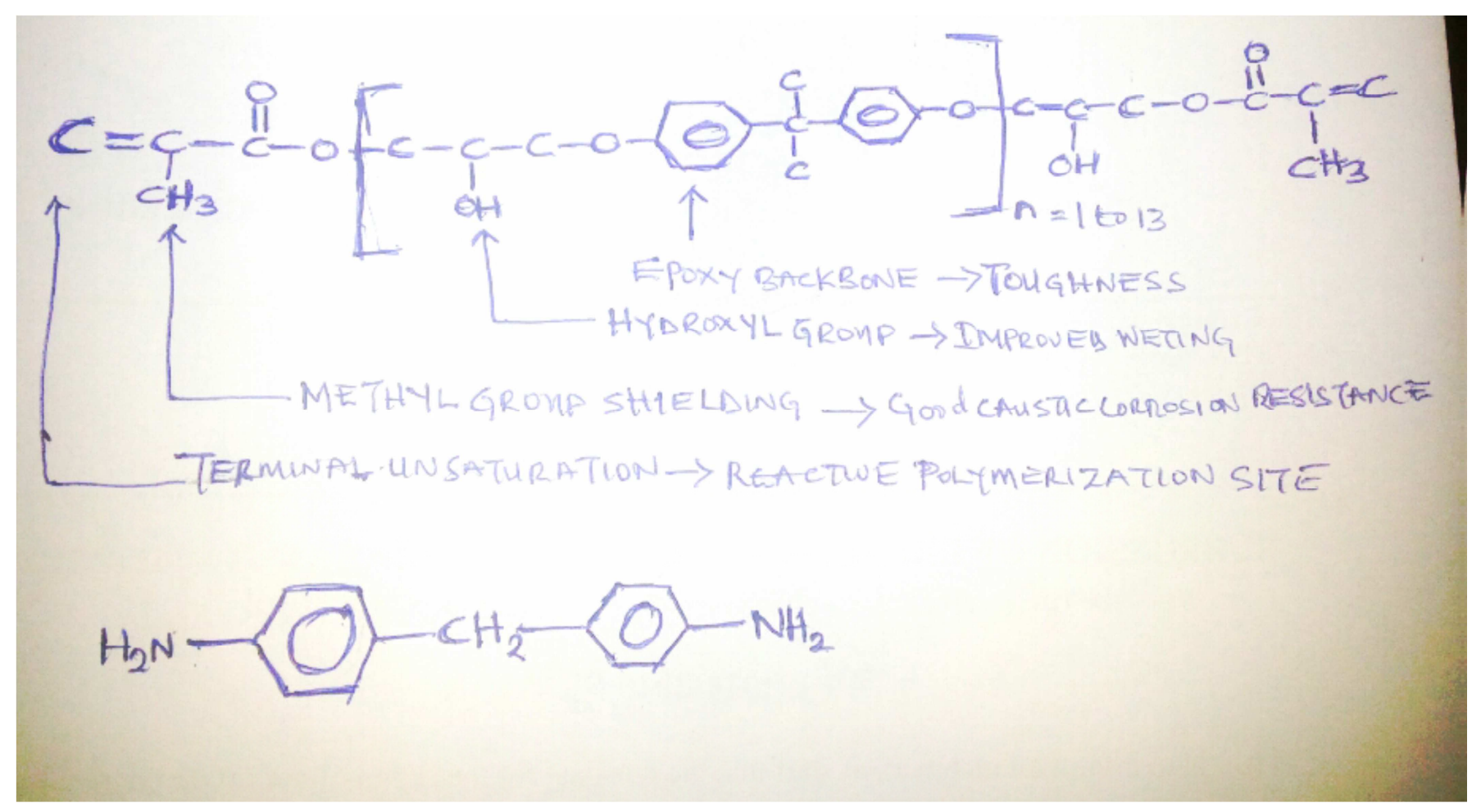

Source: [5]

Figure 1.2. Structure of DGEBA epoxy and DDM hardener.

The aim of the study is to determine the effect of microwave post curing on the cure cycle of the unsaturated polyester composites reinforced with aluminum and carbon black. This effect was compared with that post cured using conventional oven with the objectives of:

Examine the effect of bulk thickness and density of the fillers on the effectiveness of the heating methods

Determine the effect of heating rate and control of temperature on the curing of both composites

Determine the effectiveness of microwave heating in the curing time of the produced composites.

\section{Literature Review}

\section{Microwave -Material Interaction}

The material properties of greatest importance in microwave processing of a dielectric are the complex relative permittivity (e) and the loss tangent (tan d). The real part of the permittivity, sometimes called the dielectric constant, mostly determines how much of the incident energy is reflected at the air- sample interface, and how much enters the sample. The most important property in microwave processing is the loss tangent, or dielectric loss, which predicts the ability of the material to convert the incoming energy into heat [6].

Microwave energy is transferred to the material by interaction of the electromagnetic field at the molecular level. The dielectric properties determine the effect of the electromagnetic field on the material [7]. The interaction of microwaves with a dielectric material results in translation motions of free or bound charges and rotation of the dipoles.
The resistance of these induced motions due to inertial, elastic, and frictional forces causes losses resulting in volumetric heating [8].

The power absorbed per unit volume, $\mathrm{P}\left(\mathrm{W} / \mathrm{m}^{3}\right)$ is expressed as [8]:

$$
P=\sigma[E]^{2}=2 \pi f \varepsilon_{0} \varepsilon_{r} " \tan \delta[E]^{2}
$$

where $\mathrm{E}(\mathrm{V} / \mathrm{m})$ is the magnitude of the internal field, $\sigma$ the total effective conductivity $(\mathrm{S} / \mathrm{m})$, f the frequency $(\mathrm{GHz}), \varepsilon_{0}$ the permittivity of free space $\left(\varepsilon_{0}=8.86 \times 10^{-12} \mathrm{~F} / \mathrm{m}\right), \varepsilon_{r}$ " the relative dielectric constant and tan $\delta$ the loss tangent.

Equation (1) demonstrates that the power absorbed varies linearly with the frequency, the relative dielectric constant, loss tangent and the square of the electric field.

The penetration depth of microwaves (D) at which the incident power is reduced by one half is expressed as [8]:

$$
D=\left(3 \lambda_{0} / 8.686\right) \pi \tan \delta\left(\frac{\varepsilon_{r}^{\prime \prime}}{\varepsilon_{0}}\right)^{\frac{1}{2}}
$$

where $\lambda_{0}$ is the incident or free-space wavelength [8]. The relative dielectric constant and the loss tangent are the parameters that describe the behaviour of a dielectric material under the influence of the microwave field. During heating, the relative dielectric constant and the loss tangent change with temperature [8]. The heating rate of a material placed in an electromagnetic field depends on several key parameters, more specifically di-electric loss factor $\left(\varepsilon^{\prime \prime}\right)$ of the material. This is described by [9]. 


$$
\frac{d T}{d t}=K f E^{2} \varepsilon^{\prime \prime}(T) \frac{\tan \delta}{\rho C_{v}}(T)
$$

The specific heat terms show that thermodynamic transitions such as the glass transition temperature and melting of the material will greatly affect the heating susceptibility of the material [10]. The derivation of equation 3 also assumes that the convection and conduction losses and also the heat flux due to chemical reactions are ignored.

Equation 2 and 3 are useful for judging the effect of electrical properties on microwaves power absorption, however, material processing is much more complex and interaction of microwaves with material processing is still poorly understood. The dielectric properties depend on the mobility of dipoles within the structures, as a result, the dielectric properties are functions of temperature, frequency, degree of reaction (for reacting system) [2].

\section{Methodology}

\subsection{Material and Equipment Selection}

\subsubsection{Aluminum Powder Overview}

For the purpose of this research, the flake type, known as pyro powder was used. It composed of very small particles with less than $1 \mu \mathrm{m}$. Pyro powder is better selected for composite manufacturing due to the particle sizes, which eventually contributed to the weight of the composites. Other exceptional properties in a composite manufacturing include low density, corrosion resistance, high thermal and electrical conductivity, excellent machinability, good response to variety of finishing process and ability to avoid porosity.

Table 3.1. Summary of properties and composition of Aluminum powder.

\begin{tabular}{ll}
\hline Shape & Flaky \\
\hline Composition & $\mathrm{Al}_{2} \mathrm{O}_{3}$ due to strong affinity for oxygen, Polystyrene, Stearin. \\
Appearance & Silvery white and odourless powder \\
Particle Size $(\mu \mathrm{m})$ & $<1 \mu \mathrm{m}$ \\
True Density $\left(\mathrm{g} / \mathrm{cm}^{3}\right)$ & 2.70 \\
Boiling Point $\left({ }^{\circ} \mathrm{C}\right)$ & 2467 \\
Melting Point $\left({ }^{0} \mathrm{C}\right)$ & 660.1 \\
MolecularWeight $(\mathrm{g} / \mathrm{mol})$ & 29.92 \\
Specific Heat $@ 25^{\circ} \mathrm{C}\left(\mathrm{Cal} / \mathrm{g}^{0} \mathrm{C}\right)$ & 0.215 \\
Thermal Conductivity $@ 20^{0} \mathrm{C}\left(\mathrm{Cal} / \mathrm{s} . \mathrm{cm} .{ }^{0} \mathrm{C}\right)$ & 0.50 \\
Co-efficient of Expansion@ $@ 20-100$ deg.C & 24.0 \\
Modulus of Elasticity & 69 \\
Specific gravity & 2.6989 \\
Crystallography & Cubic structure, face centred \\
\hline
\end{tabular}

\subsubsection{Polyester Resin Overview}

There are two principal types of polyester resin used as standard laminating systems in the composite industry. Orthophthalic polyester resin is the standard economic resin used by many people. Isophthalic polyester resin is now becoming the preferred material in industries such as marine where its superior water resistance is desirable. Most polyester resins are viscous, pale coloured liquids consisting of a solution of polyester in monomer which is usually styrene. The addition of styrene in amount of up to $50 \%$ helps to make the resin easier to handle by reducing its viscosity [11]. The styrene also performs the vital function of enabling the resin to cure from a liquid to solid by cross linking the molecular chains of the polyester, without the evolution of any by products. For the purpose of the research work, the Orthophthalic type of polyester is used (M3903 unsaturated polyester resin).

Table 3.2. Summary of properties and Composition of M3903 Polyester resin.

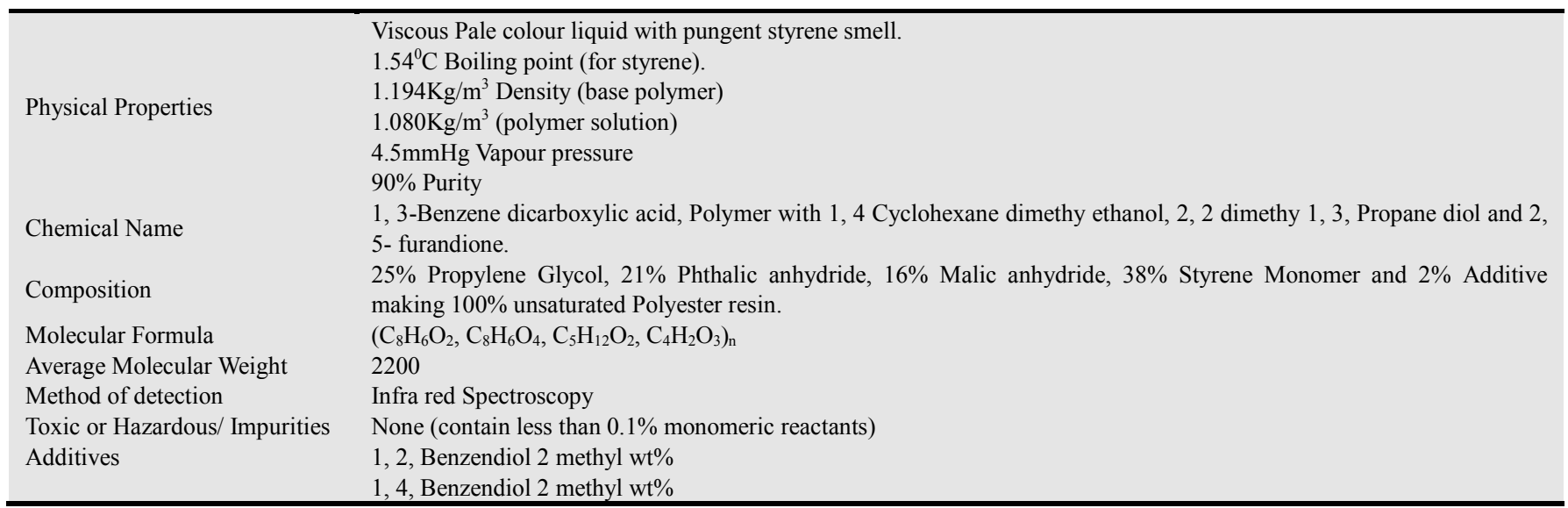




\subsubsection{Carbon Black Overview}

There are two major types of carbon black namely, thermal black and furnace black. For the purpose of this study, furnace black was used. The reaction time for the production of thermal black is long in compares to the furnace black process. Long reaction time combined with the high temperature required for the thermal decomposition of natural gas feed stock $\left(1300^{\circ} \mathrm{C}\right)$ allows the graphite layer planes of the thermal black to become highly ordered so that only layer surfaces are at the surface of the particle. Conversely, the shorter reaction time used in making furnace black produce layer planes at the surface which are less ordered, resulting in numerous sites for chemical bonds with elastromers. Carbon black with a high amount of surface activity often provides high reinforcement [11]. While thermal black does impart some degree of reinforcement to elastromer.It is most often referred to as an inactive or non- reinforcing black. Other materials include cobalt accelerator and organic peroxide catalyst (MEKP) all mixed in the right proportions.

\subsection{Composite Manufacturing Process}

\section{Mould Description}

The mould used for the production of the composites is 3gang $2 \times 2$ inches $(50 \mathrm{~mm})$ mould, machined out of brass makes 3 compression test cubes at once. This mould cast cubes in a diagonal arrangement with a detachable brass base plate. Wing nut clamps lock the mould to the base while stainless thumb screws secure halves tightly together. Large screened off upper surface area makes this mould a preferred choice. Optional accessories include an all brass fitted top, or cover plate designed to pour molten substance capping compound down through taper hole for testing tensile strength.

Table 3.3. Mixing ratio of Polyester Resin, Hardener and Conducting Fillers.

\begin{tabular}{lllll}
\hline $\begin{array}{l}\text { Percentages of Conducting } \\
\text { Fillers (\%) }\end{array}$ & $\begin{array}{l}\text { Weight fraction of } \\
\text { Polyester Resin }(\mathbf{g})\end{array}$ & $\begin{array}{l}\text { Weight fraction of } \\
\text { Accelerator/catalyst (g) }\end{array}$ & $\begin{array}{l}\text { Weight fraction of Conducting Fillers } \\
\text { (Aluminium and Carbon Black) (g) }\end{array}$ & \begin{tabular}{l} 
Composites \\
\hline 10
\end{tabular} \\
394 & 56 & 50 & 500 \\
20 & 320 & 80 & 100 & 500 \\
30 & 263 & 88 & 150 & 500 \\
\hline
\end{tabular}

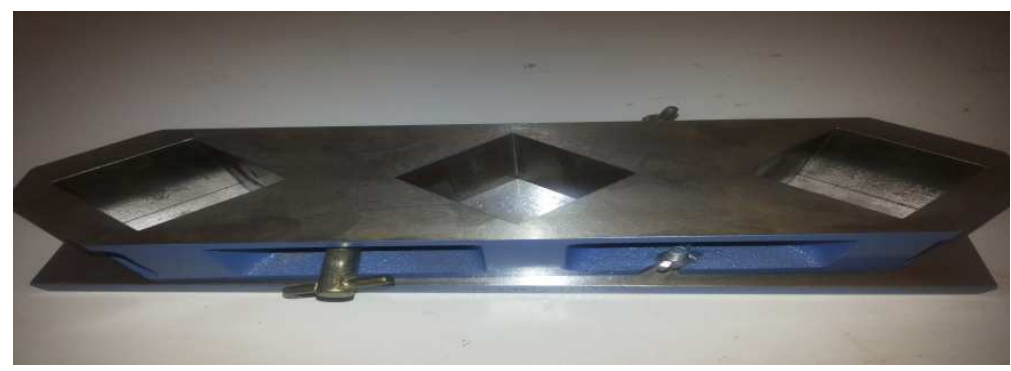

Figure 3.1. 3-gang Mould.

The following are the set of sequential steps for the composites manufacturing process:

i. The fabricated moulds are properly prepared and clean

ii. Correct amount of fillers (Aluminum and Carbon black) are weighed into containers (figure 3.2)

iii. Correct amount of polyester resin, hardener and other additives are weighed and mixed together (figure 3.3)

iv. Resin and filler are evenly and slowly mixed with the aid of strong metallic spoon in order to ensure a homogeneous composite mixture (figure 3.4)

v. Each mixture is poured into moulds and allowed to precure under ambient temperature for $24 \mathrm{hrs}$ (figure $3.5 \& 3.6)$

vi. The pre-cured samples were removed from the moulds and transferred into the ovens for post curing. The detail post curing temperature and time reflect in the results section of the article (figure 3.7-3.11).

Alongside with the post curing is the characterization of the composite samples where the temperature profiles and cure characteristics were determined.
The temperature is monitored and recorded using hand laboratory thermometer of $300^{\circ} \mathrm{C}$ graduation, while the cure characteristics were conducted with differential scanning Calorimetry under isothermal condition.

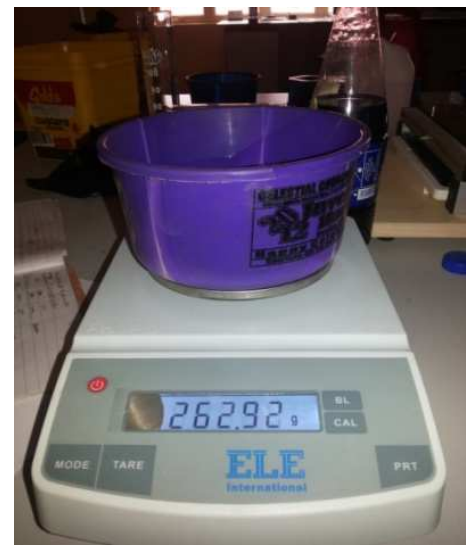

Figure 3.2. Conducting fillers measurement in progress. 

Reinforced Polymer Matrix Composites

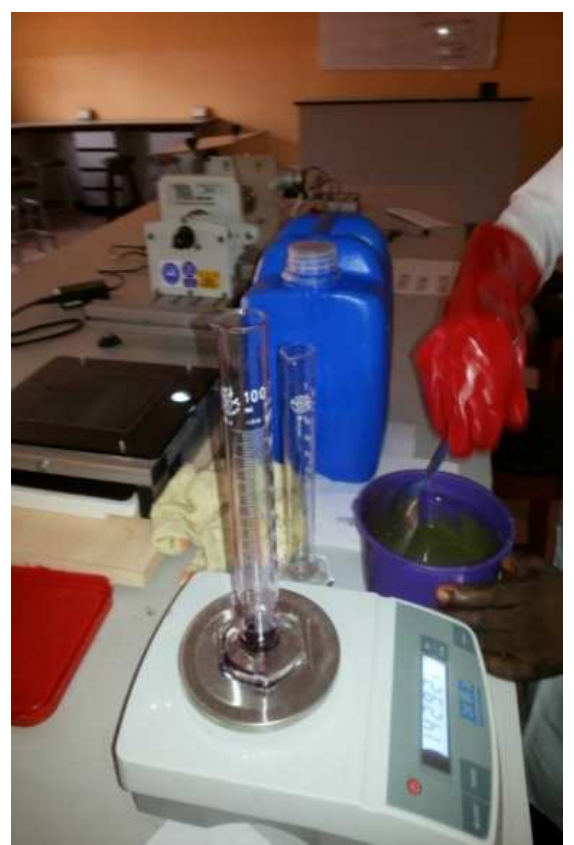

Figure 3.3. Hardeners measurement in progress.

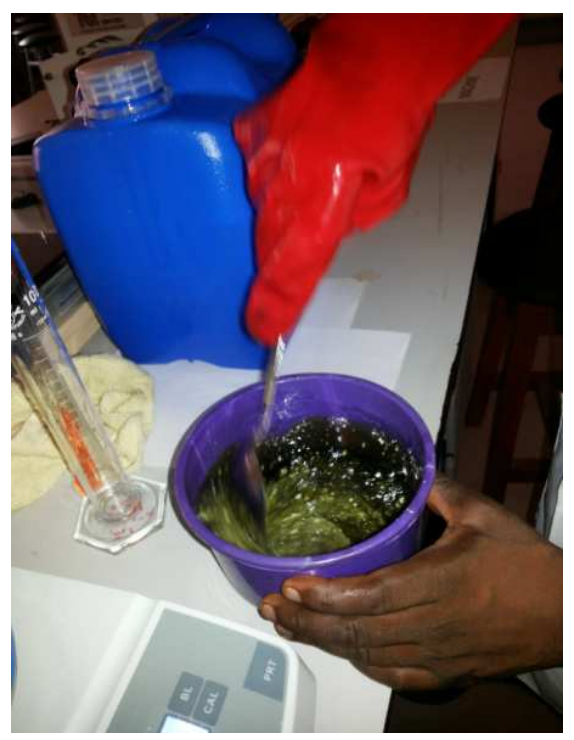

Figure 3.4. Mixing of the Composites in Progress.

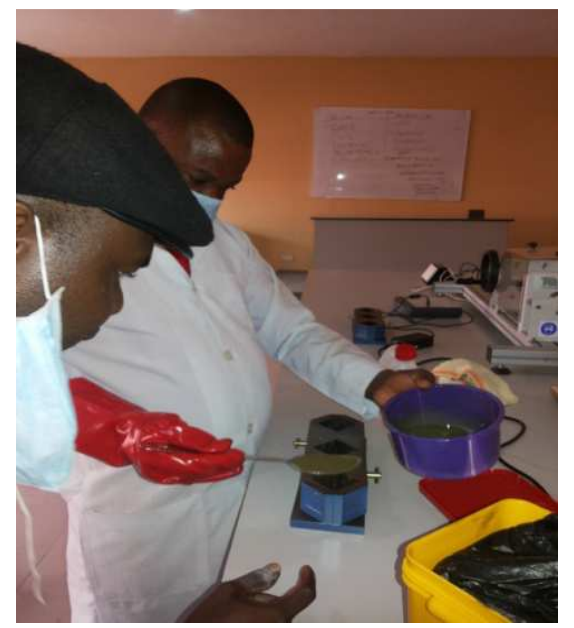

Figure 3.5. Composites Lamination in Progress.

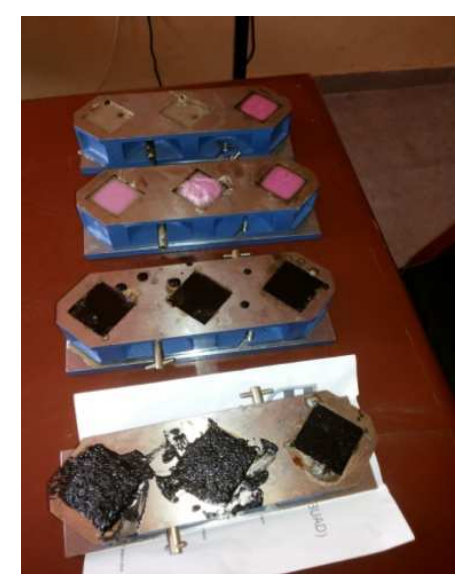

Figure 3.6. Pre-Cured Samples.

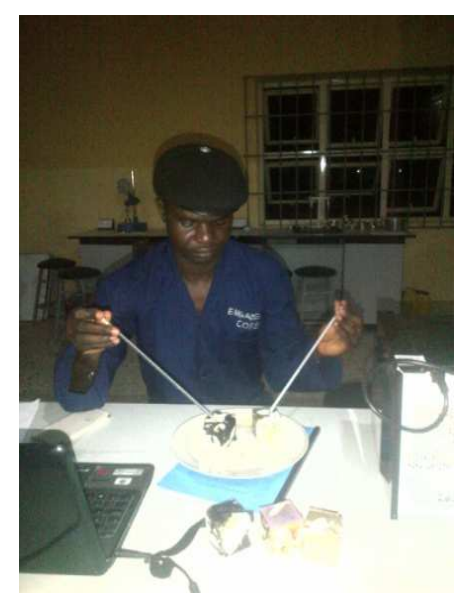

Figure 3.7. Temperature Measurement in Progress.

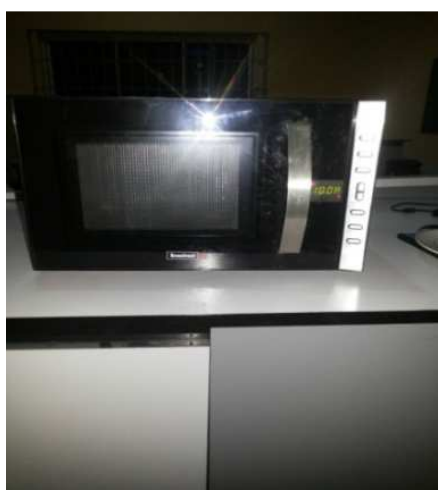

Figure 3.8. Microwave Oven Curing in Progress.

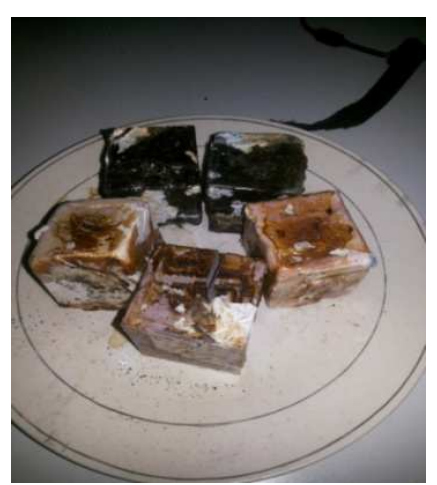

Figure 3.9. Post-Cured Samples. 


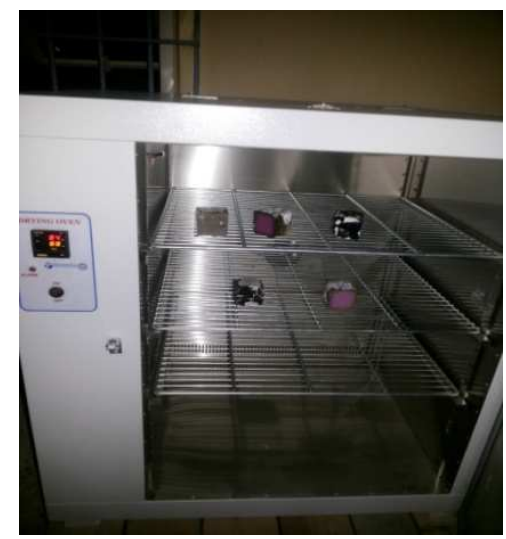

Figure 3.10. Conventional Oven Curing in Progress.

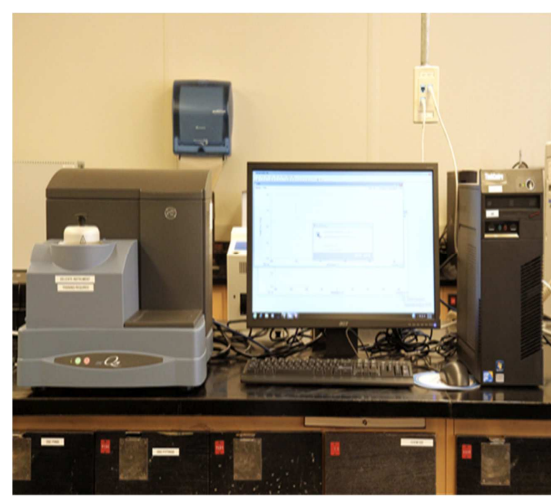

Figure 3.11. Diagram Differential scanning calorimeter.

\section{Results and Results Discussion}

Table 4.1. Temperature Profiles for Microwave Heating.

\begin{tabular}{|c|c|c|c|c|c|c|c|c|c|}
\hline \multicolumn{2}{|c|}{$\begin{array}{l}\text { 30\% Aluminum Filled } \\
\text { Polyester }\end{array}$} & \multicolumn{2}{|c|}{$\begin{array}{l}\text { 20\% Aluminum Filled } \\
\text { Polyester }\end{array}$} & \multicolumn{2}{|c|}{$\begin{array}{l}10 \% \text { Aluminum Filled } \\
\text { Polyester }\end{array}$} & \multicolumn{2}{|c|}{$\begin{array}{l}20 \% \text { Carbon Black Filled } \\
\text { Polyester } \\
\end{array}$} & \multicolumn{2}{|c|}{$\begin{array}{l}10 \% \text { Carbon Black Filled } \\
\text { Polyester }\end{array}$} \\
\hline Time (min) & Temp $\left({ }^{0} \mathrm{C}\right)$ & Time (min) & Temp $\left({ }^{0} \mathrm{C}\right)$ & Time (min) & Temp $\left({ }^{\circ} \mathrm{C}\right)$ & Time (min) & Temp $\left({ }^{0} \mathrm{C}\right)$ & Time (min) & Temp $\left({ }^{0} \mathrm{C}\right)$ \\
\hline 5 & 30 & 5 & 30 & 5 & 32 & 5 & 45 & 5 & 50 \\
\hline 10 & 55 & 10 & 50 & 10 & 40 & 10 & 70 & 10 & 70 \\
\hline 15 & 94 & 15 & 92 & 15 & 84 & 15 & 70 & 15 & 70 \\
\hline 20 & 94 & 20 & 92 & 20 & 84 & - & - & - & - \\
\hline
\end{tabular}

Table 4.2. Temperature Profiles for Conventional Heating.

\begin{tabular}{|c|c|c|c|c|c|c|c|c|c|}
\hline \multicolumn{2}{|c|}{$\begin{array}{l}\text { 30\% Aluminum Filled } \\
\text { Polyester }\end{array}$} & \multicolumn{2}{|c|}{$\begin{array}{l}\text { 20\% Aluminum Filled } \\
\text { Polyester }\end{array}$} & \multicolumn{2}{|c|}{$\begin{array}{l}\text { 10\% Aluminum Filled } \\
\text { Polyester }\end{array}$} & \multicolumn{2}{|c|}{$\begin{array}{l}20 \% \text { Carbon Black Filled } \\
\text { Polyester }\end{array}$} & \multicolumn{2}{|c|}{$\begin{array}{l}\text { 10\% Carbon Black Filled } \\
\text { Polyester }\end{array}$} \\
\hline Time (min) & Temp ( $\left({ }^{\circ} \mathrm{C}\right)$ & Time (min) & Temp $\left({ }^{0} \mathrm{C}\right)$ & Time (min) & Temp $\left({ }^{\circ} \mathrm{C}\right)$ & Time (min) & Temp ( $\left.{ }^{\circ} \mathrm{C}\right)$ & Time (min) & Temp $\left({ }^{0} \mathrm{C}\right)$ \\
\hline 5 & 32 & 5 & 33 & 5 & 32 & 5 & 34 & 5 & 34 \\
\hline 10 & 39 & 10 & 39 & 10 & 40 & 10 & 40 & 10 & 40 \\
\hline 20 & 44 & 20 & 45 & 20 & 42 & 20 & 50 & 20 & 45 \\
\hline 30 & 52 & 30 & 54 & 30 & 50 & 30 & 52 & 30 & 50 \\
\hline 50 & 58 & 50 & 58 & 50 & 58 & 50 & 60 & 50 & 60 \\
\hline 110 & 62 & 110 & 62 & 110 & 62 & 110 & 68 & 110 & 65 \\
\hline 170 & 70 & 170 & 68 & 170 & 68 & 170 & 70 & 170 & 70 \\
\hline 230 & 80 & 230 & 78 & 230 & 80 & 230 & 70 & 230 & 70 \\
\hline 290 & 86 & 290 & 90 & 290 & 88 & - & - & - & - \\
\hline 350 & 86 & 350 & 90 & 350 & 88 & - & - & - & - \\
\hline
\end{tabular}

Table 4.3. Degree of Cure Profiles for Microwave Heating.

\begin{tabular}{|c|c|c|c|c|c|c|c|c|c|}
\hline \multicolumn{2}{|c|}{$\begin{array}{l}\text { 30\% Aluminum Filled } \\
\text { Polyester }\end{array}$} & \multicolumn{2}{|c|}{$\begin{array}{l}\text { 20\% Aluminum Filled } \\
\text { Polyester }\end{array}$} & \multicolumn{2}{|c|}{$\begin{array}{l}\text { 10\% Aluminum Filled } \\
\text { Polyester }\end{array}$} & \multicolumn{2}{|c|}{$\begin{array}{l}\text { 20\% Carbon Black Filled } \\
\text { Polyester }\end{array}$} & \multicolumn{2}{|c|}{$\begin{array}{l}\text { 10\% Carbon Black Filled } \\
\text { Polyester }\end{array}$} \\
\hline Time (min) & $\begin{array}{l}\text { Degree of } \\
\text { Cure }(\%)\end{array}$ & Time (min) & $\begin{array}{l}\text { Degree of } \\
\text { Cure }(\%)\end{array}$ & Time (min) & $\begin{array}{l}\text { Degree of } \\
\text { Cure }\left({ }^{\%}\right)\end{array}$ & Time (min) & $\begin{array}{l}\text { Degree of } \\
\text { Cure }(\%)\end{array}$ & Time (min) & $\begin{array}{l}\text { Degree of } \\
\text { Cure }(\%)\end{array}$ \\
\hline 5 & 0.25 & 5 & 0.25 & 5 & 0.3 & 5 & 0.5 & 5 & 0.3 \\
\hline 10 & 0.6 & 10 & 0.5 & 10 & 0.4 & 10 & 0.8 & 10 & 0.75 \\
\hline 15 & 0.94 & 15 & 0.9 & 15 & 0.8 & 15 & 0.8 & 15 & 0.75 \\
\hline 20 & 0.94 & 20 & 0.9 & 20 & 0.8 & - & - & - & - \\
\hline
\end{tabular}


Table 4.4. Degree of Cure Profile for Conventional Heating Method.

\begin{tabular}{|c|c|c|c|c|c|c|c|c|c|}
\hline \multicolumn{2}{|c|}{$\begin{array}{l}\text { 30\% Aluminum Filled } \\
\text { Polyester }\end{array}$} & \multicolumn{2}{|c|}{$\begin{array}{l}\text { 20\% Aluminum Filled } \\
\text { Polyester }\end{array}$} & \multicolumn{2}{|c|}{$\begin{array}{l}\text { 10\% Aluminum Filled } \\
\text { Polyester }\end{array}$} & \multicolumn{2}{|c|}{$\begin{array}{l}\text { 20\% Carbon Black Filled } \\
\text { Polyester }\end{array}$} & \multicolumn{2}{|c|}{$\begin{array}{l}10 \% \text { Carbon Black Filled } \\
\text { Polyester }\end{array}$} \\
\hline Time (min) & $\begin{array}{l}\text { Degree of } \\
\text { Cure }\left({ }^{\%}\right)\end{array}$ & Time (min) & $\begin{array}{l}\text { Degree of } \\
\text { Cure }\left({ }^{\%}\right)\end{array}$ & Time (min) & $\begin{array}{l}\text { Degree of } \\
\text { Cure }\left({ }^{\%}\right)\end{array}$ & Time (min) & $\begin{array}{l}\text { Degree of } \\
\text { Cure }\left({ }^{\%}\right)\end{array}$ & Time (min) & $\begin{array}{l}\text { Degree of } \\
\text { Cure }\left({ }^{\%}\right)\end{array}$ \\
\hline 5 & 0.2 & 5 & 0.25 & 5 & 0.33 & 5 & 0.3 & 5 & 0.33 \\
\hline 10 & 0.4 & 10 & 0.4 & 10 & 0.42 & 10 & 0.4 & 10 & 0.4 \\
\hline 20 & 0.5 & 20 & 0.48 & 20 & 0.45 & 20 & 0.5 & 20 & 0.48 \\
\hline 30 & 0.55 & 30 & 0.50 & 30 & 0.50 & 30 & 0.65 & 30 & 0.58 \\
\hline 50 & 0.65 & 50 & 0.62 & 50 & 0.60 & 50 & 0.70 & 50 & 0.68 \\
\hline 110 & 0.75 & 110 & 0.70 & 110 & 0.69 & 110 & 0.78 & 110 & 0.72 \\
\hline 170 & 0.85 & 170 & 0.80 & 170 & 0.80 & 170 & 0.82 & 170 & 0.75 \\
\hline 230 & 0.96 & 230 & 0.92 & 230 & 0.92 & 230 & 0.82 & 230 & 0.75 \\
\hline \multirow[t]{2}{*}{290} & 0.96 & 290 & 0.92 & 290 & 0.92 & - & - & - & - \\
\hline & & & & & & - & - & - & - \\
\hline
\end{tabular}

\subsection{Discussion of Results}

Table 4.1 and 4.2 show the temperature profiles data for both microwaves curing and conventional curing respectively. These show the responses of the composites (aluminum filled polyester and carbon black filled polyester composites) to heat in terms of rate of heat transfer and heat stability. From the table, temperature profiles of the composites for different weight fraction $(30 \%, 20 \%$ and $10 \%)$ of the particulate reinforcement were also indicated. This is performed to determine the effect of bulk thickness and density on heating effectiveness.

For microwaves curing of the composites, the temperature of the microwave was initially set at $20^{\circ} \mathrm{C}$ for the first 5 minutes. This is to ensure all samples achieve specified temperature, uniform heating rate and avoids unnecessary sample burn-out [12]. The subsequent heating was carried out $60^{\circ} \mathrm{C}$ after which the samples have assumed uniform initial temperature.

For conventional thermal oven curing, the temperature of the oven was initially set at $80^{\circ} \mathrm{C}$ for the first five minutes. The temperatures of the samples were recorded at a progressive time-interval of $5,10,20,30,50$ and constant interval of 60 minutes just to minimize undue lengthy processing time. The temperature of the oven was later fixed at $120^{\circ} \mathrm{C}$. This was because some composites respond to temperature faster, and not to hinder the curing process, the operating temperature of the oven must be able to accommodate the ultimate cure temperature of the composites.

Table 4.2 and 4.3 show the cure characteristic profile data for both microwaves and conventional curing in terms of degree of cure respectively. This shows the response of the composites to rate of curing $(\delta \alpha / \delta \mathrm{t})$. The tables also show degree of cure of the composites for different weight fractions of the particulate reinforcement.

Conventional Differential Scanning Calorimeter (Openstax-CNX module M43558) was used to obtain the degree of cure for both the microwave and conventionally cured samples. DSC scans were carried out under isothermal condition of $120^{\circ} \mathrm{C}$ at regular time intervals as the heating rate throughout the process.

Comparison of Temperature Profiles between the Microwave and Conventional Heating for PolyesterAluminum Composite and Polyester- Carbon black Composites

Figure $4.1 \mathrm{a} \& \mathrm{~b}$ show the microwave heating rate curves for varying weight fractions of aluminum filled polyester and carbon black filled polyester composites. From the curves, the bulk thickness of the constituent material of the composites really have impact on the heating rate, thus on the effectiveness of the heating methods. It was observed that $10 \%$ aluminum filled and $20 \%$ carbon black filled polyester composites have the most temperature of $33^{\circ} \mathrm{C}$ and $50^{\circ} \mathrm{C}$ recorded at the initial five minute. This is backed up by [2] that material with high dielectric loss factor is difficult to heat from room temperature. $10 \%$ aluminum filled polyester has the least dielectric loss factor while $30 \%$ aluminum filled has the most dielectric loss factor in the metallic matrix composites and also $20 \%$ carbon black filled polyester has the least dielectric loss factor in the non metallic matrix composites. This is best explained as the dielectric loss factor of material quantifies the ability of material to dissipate electrical energy into thermal energy [2]. When an alternating electric field is applied to the material with dipole moments, they try to cancel the field by following the changing direction of the field [13]. The re orientation and the distortion of the dipoles produce frictional heat, hence dissipation of supplied electromagnetic energy. This type of loss of energy is called dielectric loss [13], [2]. Microwave heating of materials is governed by the principle that the dielectric power absorption of the material is proportional to it dielectric loss factor, which determines the rate of conversion of electrical energy into thermal energy in the material. As the curing progresses, it was observed that the trend of the highest heating rate changed to $30 \%$ aluminum filled polyester composite, followed by $20 \%$ aluminum filled polyester 
composite. This is due to the fact that there were more cross linking reactions with higher percentage weight fraction of

particulate reinforcement.

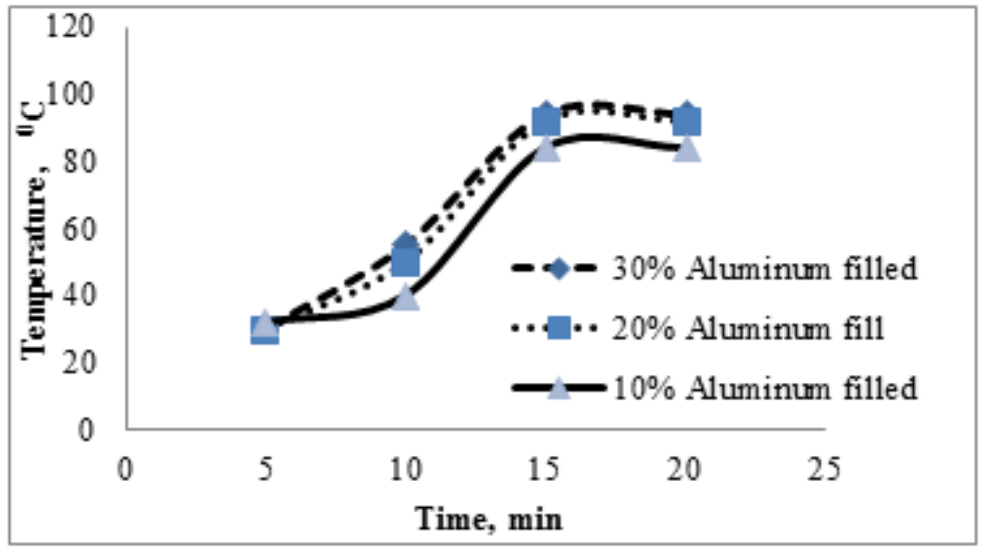

Figure 4.1a. Microwave Heating Rate Curve for varying weight fractions of Aluminum filled Polyester-Resin.

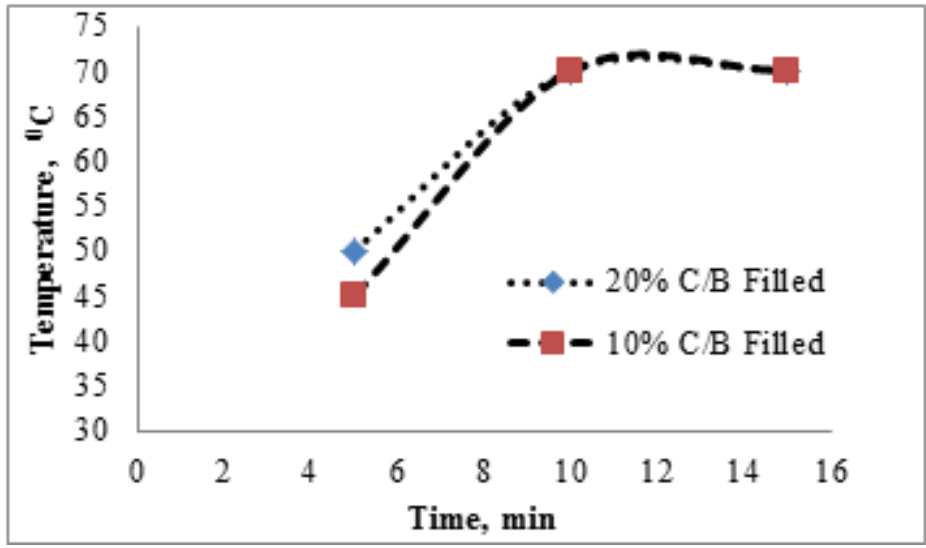

Figure 4.1b. Microwave Heating Rate Curve for varying weight fractions of Carbon Black filled Polyester-Resi.

The high rate of heat transferred through the material was therefore as a result of aggregate of volumetric heating from the microwave system and total exothermic heat of reaction due to cross-linking reaction [14].

Figure $4.1 \mathrm{a} \& \mathrm{~b}$ also show that variation in percentage weight fraction of the reinforcement has little impact on cure temperature but insignificant of cure time. $30 \%$ aluminum filled cured at $94^{\circ} \mathrm{C}, 20 \%$ aluminum filled cure $92^{\circ} \mathrm{C}$, while $10 \%$ aluminum filled cured at $84^{\circ} \mathrm{C}$. Also carbon black filled polyester composite shows appreciable cure cycle in microwave and conventional heating as compared to aluminum filled polyester composite.

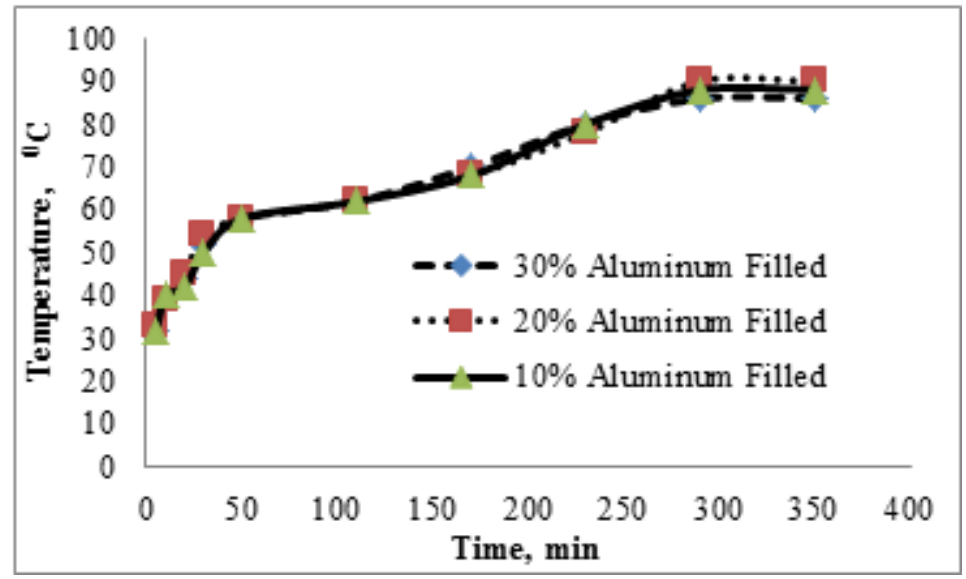

Figure 4.2a. Conventional Heating Rate Curve for varying weight fractions of Aluminum filled Polyester-Resin. 


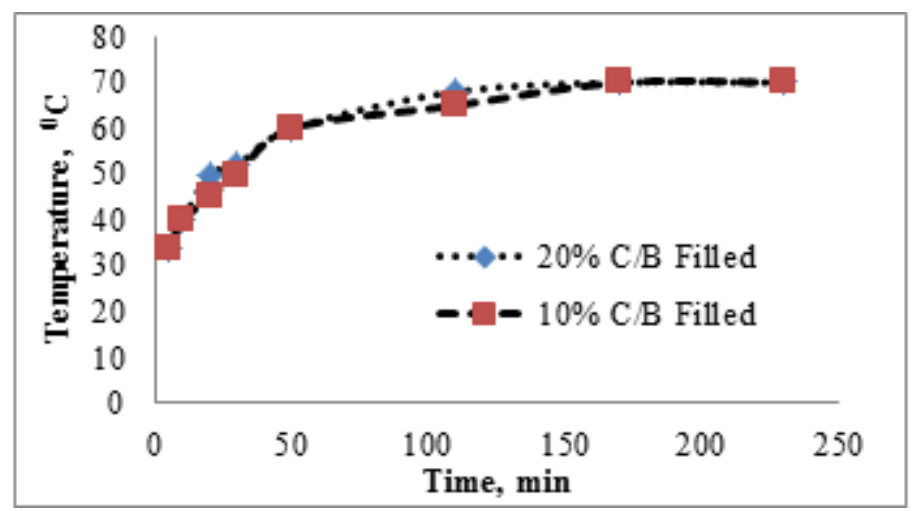

Figure 4.2b. Conventional Heating Rate Curve for varying weight fractions of Carbon Black filled Polyester-Resin.

Figure $4.2 \mathrm{a} \& \mathrm{~b}$ show the temperature profiles for conventional heating of aluminium filled polyesterand carbon black filled polyester composites. Figure $4.2 \mathrm{a} \& \mathrm{~b}$ show that there were serious overlapping in temperature in between the samples and gradual increase in temperature as a function of time for conventional curing in respective of variation in the percentage weight fraction of the reinforcement. It indicate that the process control developed for the conventional heating system was able to achieve temperature stability and uniform heating in the composite samples. At the end of the curing cycle, as the samples became cured, the temperature profile gradually decreased. This decrease was most likely due to formation of rigid net work structure which certainly will hindered the dipolar group motion resulting in less interaction between the electric field and dipolar molecules[2].

Comparing the curing of the composites using microwave and conventional methods, it took 20 minutes and 15 minutes for aluminium filled polyester and carbon black filled polyester composites respectively to reach ultimate cure in microwave system as compared to conventional oven system that takes the composite samples 290 minutes and 170 minutes respectively to get to the ultimate cure. This is best explained by the argument of Philips [15] that microwave generates heat through electromagnetic energy from the magnetron and applicator of the system, thus causing volumetric heating of the samples. The conventional curing method involved exposing the surface of the part to an external source of heat. Heat transport to the interior of the parts occurred by conduction. This process requires that surface temperature exceed interior temperature for the production cycle [15]. The rate of heating is dependent on its temperature gradient, some polymer matrix will be damage if exposed to excessive temperature, heating rate must be restrained so that no portion of the part exceeds the temperature limit.

Comparison of Cure Characteristic between the Microwave and Conventional Heating for PolyesterAluminum Composite and Polyester- Carbon black Composites

Figure 4.3 and 4.4 show the scan results to obtain degree of cure $(\alpha)$ as a function of time. These figures show plots of $\alpha$ as a function of curing time for varying percentage weight fraction of aluminum filled polyester and carbon black filled polyester composites for both microwave and conventional heating methods. These shoe when the samples reached ultimate degree of cure. It was observed that similar ultimate degrees of cures were obtained per percentage weight fraction of the fillers for all the samples regardless of methods of curing.

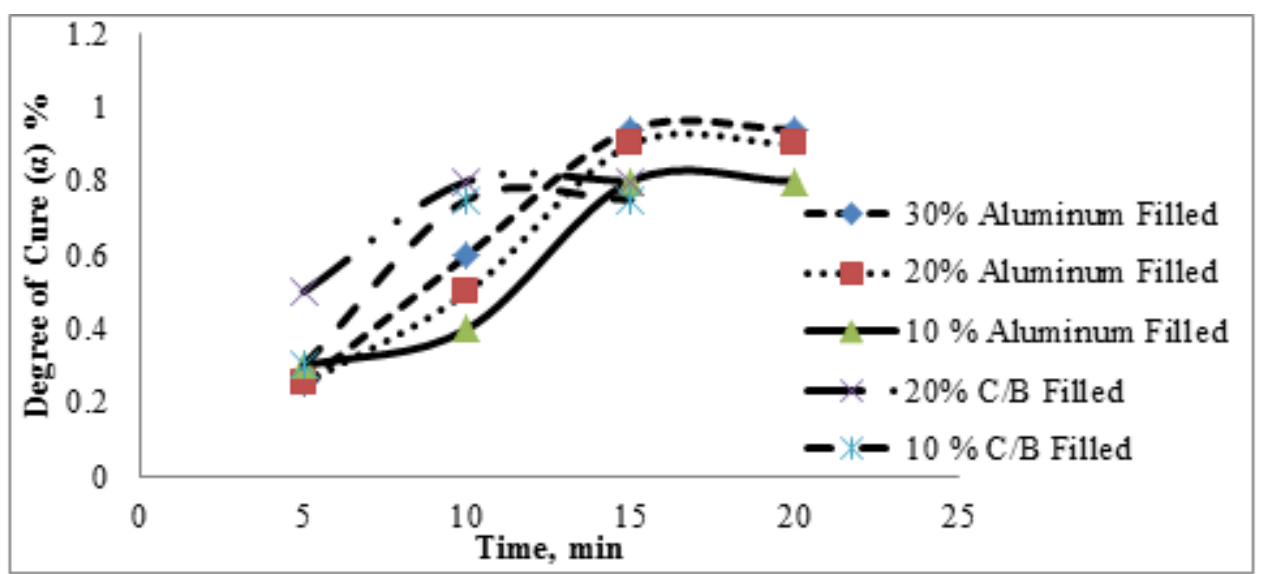

Figure 4.3. Microwave heating Cure Characteristics Curve for varying weight fractions of Aluminium filled Polyester and Carbon Black filled Polyester Composites. 


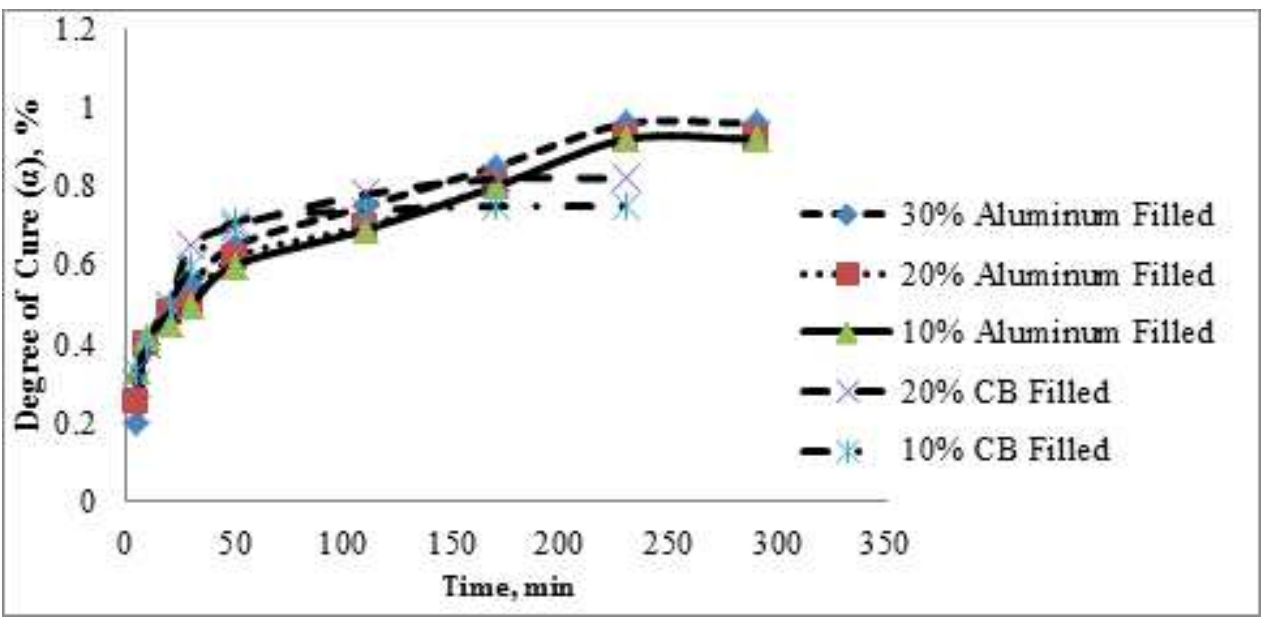

Figure 4.4. Conventional heating Cure Characteristics Curve for varying weight fractions of Aluminium filled Polyester and Carbon Black filled Polyester Composites.

Table 4.5. Cure Cycles and Ultimate cures for Different Processing Methods for Aluminum filled Polyester and Carbon-Black filled Polyester Composite Systems.

\begin{tabular}{lllll}
\hline \multirow{2}{*}{ Processing Method } & \multicolumn{2}{c}{$\%$ Weight Fraction of Filler in the composite systems } & \multirow{2}{*}{ Actual Cure Cycle (min) } \\
\cline { 2 - 5 } & $\mathbf{3 0 \%}$ & $\mathbf{2 0 \%}$ & $\mathbf{1 0 \%}$ & 15 \\
\hline Microwaves (Aluminum/Polyester) & 94 & 90 & 80 & 230 \\
Conventional (Aluminum/Polyester) & 96 & 92 & 82 & 10 \\
Microwaves (Carbon-Black/Polyester) & & 80 & 75 & 170 \\
Conventional (Carbon-Black/Polyester) & & 82 & 75 & \\
\hline
\end{tabular}

Figure 4.3 and 4.4 show that the microwave cure reaction occurred at faster rate compared to the conventional thermal cure. These results are in agreement with those found in literatures [13], [10], [16], [17] where it has been suggested that direct molecular excitation by microwave irradiation greatly shortened the curing time. In the curing of composite panels, microwave radiation heats polymer molecules directly because of the relaxation of the polarized polymer dipoles along the electric field [2]. Thus, the local molecular temperature, which was the effective temperature for the polymerization reaction would be higher in microwave heating than in conventional thermal heating resulting in faster reaction rate in microwave heating [18].

Another reason is that, in conventional heating, heat transfer is very slow because of poor thermal conductivity of the resin [2]

\subsection{Conclusions}

1. Varying percentage weight fraction of the fillers which determine the bulk thickness and density of the composites have great impact on the effectiveness of the heating regardless the method of heating. It has impact on the cure temperature $\left(\mathrm{T}_{0}\right)$ and ultimate degree of cure but little significant when it comes to time of cure

2. Good heating rate and better control of temperature were observed during the microwave curing of both composite systems as compared to the conventional curing
3. The actual cure cycle was reduced from 230 minutes to 15 minutes for curing aluminum filled polyester composites and from 170 minutes to 10 minutes for curing carbon-black filled polyester composites when using microwave heating

4. Similar glass transition temperature $(\mathrm{Tg})$ and ultimate degree of cure $(\alpha)$ were obtained from composites cured using both microwave and conventional thermal methods

\section{Recommendations}

The modeling of the composite curing process is required prior to composite production as this would help in establishing correct production parameters and method of curing thereby eliminating costly trial and producing an effective method of producing polymeric composite.

Optimization of the production process can be further developed to minimize the processing time so as to the increase in the yield of the products without compromising the production requirement.

\section{References}

[1] Kwack M., Robinson P., Bismarck A., Wise R., (2011). Curing of composite materials using the recently developed Haphaistos microwave. $18^{\text {th }}$ International Conference on composites materials, Korea, Aug. 21-26 
[2] Yussoff R., Aroua M., Nesbitt A.and Day R. J., (2007). Curing of polymeric composite using microwave resin transfer moulding (RTM). Journal of Engineering Science and Technology. Vol. 2, 151-163.

[3] Opalicki M., (1994). Curing Kinetics and Chemorheology of Thermoset Matrices for Composites, doctoral dissertation, Zagreb.

[4] Vergnaud J.M., Bouzon J., (1992). Cure of Thermosetting Resins: Modeling and Experiments, Springer-Verlag, Berlin

[5] Degamber, B. and Fernando, G. F. (2002). Process Monitoring of Fiber-Reinforced Polymer Composites. MRS Bulletin, May, p. $370-380$.

[6] Metaxas A C (1993). Ceramic transactions (eds)

[7] Thostenson E .T and Chou T.W (1999) Composites: Part A 30 1055

[8] Sutton, W.H., (1989). Microwave Processing of Ceramics, Ceramic Bulletin, 68(2), 376-86.

[9] Chen M., Siochi E.J., Ward T.C and McGrath J. E., (1993). Journal of Polymer Engineering and Science. 33,1092.

[10] Suckley, D.R. (2000). Microwave Processing of the Araldite LY5052:HY5052 Epoxy Resin System. M. Sc. Dissertation. UMIST, United Kingdom.

[11] National Research Centre (NRC) (1994), Microwave Processing of Materials, National Materials Advisory Board, Commission on Engineering and Technical Systems, National Academy Press, USA, pp.1-7, 11-2, 100, 105.
[12] Kwok Yeung Peter Wong, (2012). Measurement of mechanical electrical and thermal properties of glass powder reinforced epoxy composites. A MSc dissertation. University of Southern Queensland. Australia.

[13] Katakura Y., (2001). Microwave Curing of Curing of Diglycidyl Ether of Bisphenol A/4-cyclohexane-1, 2dicarboxylic Anhydride Resin System. M. Sc. Dissertation. UMIST.

[14] Adeodu A. O., Anyaeche C. O., Oluwole O. O., (2014). Modeling of Microwave Curing of unsaturated Polyester Based Composite materials as Process guide. Journal of Advancement in Engineering and Technology.1(1).

[15] Philip C.Sturman and Rexford N. Y., (1999). Induction heating of Polymer matrix composite fibre strands. SAMPE Journal, Vol. 26, No 4.

[16] Zhou J., Shi C., Mei B., Yuan R., Fu Z., (2003). Research on the Technology and Mechanical properties of the Microwaves processing of polymer. Journal of Material Processing Technology. Vol. 137(156-158).

[17] Boey F. Y. C., Yap B. H., Chia L., (1999). Microwave curing of epoxy-amine system - Effect of curing agent on the enhancement. Polymer Testing. Vol. 18, 93-109.

[18] Wei J., Hawley M. C and Demeuse M. T., (1995). Kinetics modeling and time- temperature-transformationdiagram of microwave and thermal cureepoxy resin. Polymer Engineering and Science. Vol. 35(6), 461-470. 